\title{
New optimal fourth-order iterative method based on linear combination technique
}

\author{
Ghulam Akbar Nadeem ${ }^{1}$ (D) , Faisal Ali ${ }^{1}$ (D) , Ji-Huan $\mathrm{He}^{* 2}$ (D) \\ ${ }^{1}$ Centre for Advanced Studies in Pure and Applied Mathematics, Bahauddin Zakariya University, Multan \\ 60800, Pakistan \\ ${ }^{2}$ School of Mathematics and Information Science, Henan Polytechnic University, Jiaozuo, China. \\ National Engineering Laboratory for Modern Silk, Soochow University, Suzhou, China
}

\begin{abstract}
Newton's iteration method is widely used in numerical methods, but its convergence is low. Though a higher order iteration algorithm leads to a fast convergence, it is always complex. An optimal iteration formulation is much needed for both fast convergence and simple calculation. Here, we develop a two-step optimal fourth-order iterative method based on linear combination of two iterative schemes for nonlinear equations, and we explore the convergence criteria of the proposed method and also demonstrate its validity and efficiency by considering some test problems. We present both numerical as well as graphical comparisons. Further, the dynamical behavior of the proposed method is revealed.
\end{abstract}

Mathematics Subject Classification (2020). 65HXX, 65H05, 37F10

Keywords. iterative method, nonlinear equation, order of convergence, linear combination

\section{Introduction}

Solving nonlinear equations is one of the most significant problems in the fields of science and engineering. There is a vast literature available for finding the solution of nonlinear equations and almost all analytical and numerical methods depend upon the iteration efficiency $[2,3,30,37,42]$. Though some one-step methods for nonlinear equations are much attractive $[19,21,22,31,36,52]$, an iteration process is still needed to find an even accurate solution. Iteration methods become a hot topic in both mathematics and engineering applications $[1,12-14,16,17,28,38,40,45,53,54,56,58]$, and an optimal iteration algorithm leads to both simple calculations and efficient results.

The homotopy perturbation method [4-11,15,24-27,43,44,47,55] constructs an effective iteration algorithm by guaranteeing its iteration path from the initial guess to the exact solution. The variational iteration method $[29,32,35,51]$ adopts the variational theory $[33,34]$ to find an optimal iteration formulation for differential equations. Taylor's series method [20,23] is simple, but only an infinite series solution is useful for analysis of

\footnotetext{
*Corresponding Author.

Email addresses: akbarmaths369@gmail.com (G.A. Nadeem), faisalali@bzu.edu.pk (F. Ali), hejihuan@suda.edu.cn (J. He)

Received: 05.04.2021; Accepted: 08.07.2021
} 
a complex nonlinear problem. The ancient Chinese algorithm and its modification are effective, but two initial guesses are needed [18].

One of the most powerful and well-known ancient techniques for finding the solution of nonlinear equations is the Newton's method which converges quadratically [47]:

$$
x_{n+1}=x_{n}-\frac{f\left(x_{n}\right)}{f^{\prime}\left(x_{n}\right)}, \quad \quad f^{\prime}\left(x_{n}\right) \neq 0, \quad n=0,1,2, \ldots .
$$

Porta and Ptak [48] modified the Newton's method and proposed the following cubically convergent method which needs three evaluations per iteration.

$$
x_{n+1}=x_{n}-\frac{f\left(x_{n}\right)+f\left(y_{n}\right)}{f^{\prime}\left(x_{n}\right)},
$$

where

$$
y_{n}=x_{n}-\frac{f\left(x_{n}\right)}{f^{\prime}\left(x_{n}\right)}, \quad \quad f^{\prime}\left(x_{n}\right) \neq 0, \quad n=0,1,2, \ldots .
$$

Noor and Gupta [46] modified Householder iterative method and developed the following fourth-order method which requires four evaluations per iteration.

$$
x_{n+1}=y_{n}-\frac{f\left(y_{n}\right)}{f^{\prime}\left(y_{n}\right)}-\frac{1}{2}\left[\frac{f\left(y_{n}\right)}{f^{\prime}\left(y_{n}\right)}\right]^{2}\left[\frac{f^{\prime}\left(x_{n}\right)}{f\left(x_{n}\right)}\right]\left[\frac{f^{\prime}\left(x_{n}\right)+f^{\prime}\left(y_{n}\right)}{f^{\prime}\left(y_{n}\right)}\right],
$$

where

$$
y_{n}=x_{n}-\frac{f\left(x_{n}\right)}{f^{\prime}\left(x_{n}\right)}, \quad \quad f^{\prime}\left(x_{n}\right) \neq 0, \quad n=0,1,2, \ldots .
$$

According to Kung and Turab [41] conjecture, if an iterative method has convergence order $2^{n}$ and requires $(n+1)$ functional evaluations per iteration, then it is known to be an optimal method. In 2015, Sherma and Behl [49] introduced an optimal fourth order method:

$$
x_{n+1}=x_{n}-\left[-\frac{1}{2}+\frac{9 f^{\prime}\left(x_{n}\right)}{8 f^{\prime}\left(y_{n}\right)}+\frac{3 f^{\prime}\left(y_{n}\right)}{8 f^{\prime}\left(x_{n}\right)}\right] \frac{f\left(x_{n}\right)}{f^{\prime}\left(x_{n}\right)},
$$

where

$$
y_{n}=x_{n}-\frac{2 f\left(x_{n}\right)}{3 f^{\prime}\left(x_{n}\right)}, \quad \quad f^{\prime}\left(x_{n}\right) \neq 0, \quad n=0,1,2, \ldots .
$$

Recently, a second derivative free optimal fourth-order method has been developed by Li [50]:

$$
x_{n+1}=x_{n}-\frac{\left[f\left(x_{n}\right)-f\left(y_{n}\right)\right] f\left(x_{n}\right)}{\left[f\left(x_{n}\right)-2 f\left(y_{n}\right)\right] f^{\prime}\left(x_{n}\right)},
$$

where

$$
y_{n}=x_{n}-\frac{f\left(x_{n}\right)}{f^{\prime}\left(x_{n}\right)}, \quad \quad f^{\prime}\left(x_{n}\right) \neq 0, \quad n=0,1,2, \ldots .
$$

Turkyilmazoglu also suggested a modified high-order Newton iteration algorithm [57]. In this paper, having motivation from the study of optimal iterative methods, we present an efficient and rapid convergent optimal fourth-order iterative method. Numerical as well as graphical comparisons with some existing methods of the same class are presented in order to demonstrate the effectiveness of the proposed method. We also discuss the dynamical behavior of newly constructed method for visualization of the roots of complex polynomials. 


\section{Construction of iterative method}

Consider the nonlinear equation

$$
f(x)=0 .
$$

Using Taylor's formula, equation (2.1) can be written in the form of the following coupled system:

$$
\begin{gathered}
f(x) \approx f(\gamma)+(x-\gamma) f^{\prime}(\gamma)+g(x)=0, \\
g(x)=\frac{\lambda f(x)}{f^{\prime}(\gamma)}-f(\gamma)-(x-\gamma) f^{\prime}(\gamma),
\end{gathered}
$$

where $\gamma$ is the initial guess and $\lambda$ an auxiliary parameter.

From equation (2.2), we get

$$
\begin{gathered}
x=\gamma-\frac{f(\gamma)}{f^{\prime}(\gamma)}-\frac{g(x)}{f^{\prime}(\gamma)}, \\
=c+N(x),
\end{gathered}
$$

where

$$
c=\gamma-\frac{f(\gamma)}{f^{\prime}(\gamma)},
$$

and

$$
N(x)=-\frac{g(x)}{f^{\prime}(\gamma)} .
$$

Here $N(x)$ is a nonlinear operator and can be approximated by using Taylor's series expansion about $x_{0}$ as follows:

$$
N(x)=N\left(x_{0}\right)+\sum_{k=1}^{\infty} \frac{\left(x_{i}-x_{0}\right)^{k}}{k !} N^{(k)}\left(x_{0}\right) .
$$

Our aim is to find the series solution of equation (2.1):

$$
x=\sum_{i=0}^{\infty} x_{i .},
$$

which can alternatively be expressed as

$$
x=\lim _{p \rightarrow \infty} X_{p}, \quad \text { where } X_{p}=x_{0}+x_{1}+\ldots+x_{p} .
$$

From equations (2.5), (2.8) and (2.9), we get

$$
\begin{aligned}
& \left.x=\sum_{i=0}^{\infty} x_{i}=c+N\left(x_{0}\right)+\sum_{k=1}^{\infty} \frac{\left(x_{i}-x_{0}\right)^{k}}{k !} N^{(k)}\left(x_{0}\right)\right), \text { which implies } \\
& x \approx c+N\left(x_{0}\right)+\sum_{k=1}^{\infty} \frac{\left(\sum_{i=0}^{k} x_{i}-x_{0}\right)^{k}}{k !} N^{(k)}\left(x_{0}\right) .
\end{aligned}
$$

Thus from the last relation, we have the following scheme:

$$
\left\{\begin{array}{l}
x_{0}=c \\
x_{1}=N\left(x_{0}\right), \\
x_{2}=\left(x_{0}+x_{1}-x_{0}\right) N^{\prime}\left(x_{0}\right), \\
x_{3}=\frac{\left(x_{0}+x_{1}+x_{2}-x_{0}\right)^{2}}{2 !} N^{\prime \prime}\left(x_{0}\right), \\
\vdots \\
x_{m+1}=\frac{\left(x_{0}+x_{1}+\ldots+x_{m}-x_{0}\right)^{m}}{m !} N^{(m)}\left(x_{0}\right), m=1,2, \ldots .
\end{array}\right\}
$$

Thus

$$
\begin{aligned}
x_{1}+x_{2}+\ldots+x_{m+1} & =N\left(x_{0}\right)+\left(x_{0}+x_{1}-x_{0}\right) N^{\prime}\left(x_{0}\right)+\ldots \\
+ & \frac{\left(x_{0}+x_{1}+\ldots+x_{m}-x_{0}\right)^{m}}{m !} N^{(m)}\left(x_{0}\right), \quad m=1,2, \ldots .
\end{aligned}
$$


From equation (2.6) and the first equation of (2.12), we have

$$
x_{0}=c=\gamma-\frac{f(\gamma)}{f^{\prime}(\gamma)} .
$$

Using equation (2.10) with $p=0$ and equation (2.14), we have

$$
x \approx X_{0}=x_{0}=\gamma-\frac{f(\gamma)}{f^{\prime}(\gamma)} .
$$

This formulation allows us to propose the following iterative method for solving nonlinear equation (2.1).

Algorithm 2.1. For a given $x_{0}$, compute the approximate solution $x_{n+1}$ by the following iterative scheme:

$$
x_{n+1}=x_{n}-\frac{f\left(x_{n}\right)}{f^{\prime}\left(x_{n}\right)}, \quad f^{\prime}\left(x_{n}\right) \neq 0, \quad n=0,1,2, \ldots,
$$

which is obviously the well-known Newton's method.

Using equation (2.7) and second equation of (2.12), we get

$$
x_{1}=N\left(x_{0}\right)=-\frac{g\left(x_{0}\right)}{f^{\prime}(\gamma)} .
$$

From equation (2.3),we have

$$
g\left(x_{0}\right)=\frac{\lambda f\left(x_{0}\right)}{f^{\prime}(\gamma)}-f(\gamma)-\left(x_{0}-\gamma\right) f^{\prime}(\gamma)
$$

Using equations (2.14), (2.17) and (2.18), we get

$$
x_{1}=N\left(x_{0}\right)=-\frac{\lambda f\left(x_{0}\right)}{\left(f^{\prime}(\gamma)\right)^{2}}=-\frac{\lambda f\left(\gamma-\frac{f(\gamma)}{f^{\prime}(\gamma)}\right)}{\left(f^{\prime}(\gamma)\right)^{2}} .
$$

Truncating equation (2.10) after two terms and using equations (2.14) and (2.18), we get

$$
\begin{aligned}
x & \approx X_{1}=x_{0}+x_{1} \\
& =\gamma-\frac{f(\gamma)}{f^{\prime}(\gamma)}-\frac{\lambda f\left(\gamma-\frac{f(\gamma)}{f^{\prime}(\gamma)}\right)}{\left(f^{\prime}(\gamma)\right)^{2}} .
\end{aligned}
$$

This formulation allows us to propose the following iterative method for solving nonlinear equation (2.1).

Algorithm 2.2. For a given $x_{0}$, compute the approximate solution $x_{n+1}$ by the following iterative scheme:

where

$$
x_{n+1}=y_{n}-\frac{\lambda f\left(y_{n}\right)}{\left(f^{\prime}\left(x_{n}\right)\right)^{2}},
$$

$$
y_{n}=x_{n}-\frac{f\left(x_{n}\right)}{f^{\prime}\left(x_{n}\right)}, \quad n=0,1,2, \ldots .
$$

The last algorithm has convergence order 3 corresponding to $\lambda=1$.

On the basis of the methods given in equations (1.2) and (2.21), we suggest the following new optimal fourth-order iterative scheme using linear combination of these two:

$$
x_{n+1}=x_{n}+(\mu-1) \frac{f\left(x_{n}\right)+f\left(y_{n}\right)}{f^{\prime}\left(x_{n}\right)}-\mu\left(\frac{f\left(x_{n}\right)}{f^{\prime}\left(x_{n}\right)}+\frac{\lambda f\left(y_{n}\right)}{\left(f^{\prime}\left(x_{n}\right)\right)^{2}}\right),
$$

where $\mu \in \mathbb{R}$ is the adjusting parameter. Obviously, for $\mu=0$, the method proposed above reduces to the method given in (1.2) and for $\mu=1$, it gives the method defined in equation (2.21). It is noticeable that the methods given in equations (1.2) and (2.21) are cubically convergent and require function evaluations 3 each. The above, newly suggested method also needs 3 function evaluations but its performance depends upon a suitable choice of $\mu$.

Thus for $\mu=-1$ and $\lambda=1$, the above formulation allows us to suggest the following optimal fourth-order iterative method: 
Algorithm 2.3. For a given $x_{0}$, compute the approximate solution $x_{n+1}$ by the following iterative scheme:

$$
x_{n+1}=x_{n}-\frac{f^{\prime}\left(x_{n}\right)\left(f\left(x_{n}\right)+2 f\left(y_{n}\right)\right)-f\left(y_{n}\right)}{\left(f^{\prime}\left(x_{n}\right)\right)^{2}},
$$

where

$$
y_{n}=x_{n}-\frac{f\left(x_{n}\right)}{f^{\prime}\left(x_{n}\right)}, \quad n=0,1,2, \ldots .
$$

To the best of our knowledge, algorithms 2.2 and 2.3 are new for solving nonlinear equation (2.1).

\section{Convergence analysis}

The convergence criteria for the newly proposed iterative method is described in the following theorem.

Theorem 3.1. Assume that the function $f: I \subset \mathbb{R} \rightarrow \mathbb{R}$ (where $I$ is an open interval) has a simple root $\alpha \in I$. Let $f(x)$ be sufficiently differentiable in the neighborhood of $\alpha$, then the method given in algorithm 2.3 has convergence order at least 4.

Proof of Theorem 3.1. Let $\alpha \in I$ be a simple zero of equation (2.1). Since $f$ is sufficiently differentiable, therefore, the Taylor series expansions of $f\left(x_{n}\right)$ and $f^{\prime}\left(x_{n}\right)$ about $\alpha$ are given by

$$
f\left(x_{n}\right)=f^{\prime}(\alpha)\left\{e_{n}+c_{2} e_{n}^{2}+c_{3} e_{n}^{3}+c_{4} e_{n}^{4}+c_{5} e_{n}^{5}+O\left(e_{n}^{6}\right)\right\}
$$

and

$$
f^{\prime}\left(x_{n}\right)=f^{\prime}(\alpha)\left\{1+2 c_{2} e_{n}+3 c_{3} e_{n}^{2}+4 c_{4} e_{4}^{3}+5 c_{5} e_{n}^{4}+6 c_{6} e_{n}^{5}+O\left(e_{n}^{6}\right)\right\},
$$

where

$$
e_{n}=x_{n}-\alpha \text { and } c_{j}=\frac{1}{j !} \frac{f^{(j)}(\alpha)}{f^{\prime}(\alpha)}, \quad j=2,3, \ldots .
$$

From equations (3.1) and (3.2), we get

$$
\begin{gathered}
\frac{f\left(x_{n}\right)}{f^{\prime}\left(x_{n}\right)}=e_{n}-c_{2} e_{n}^{2}+2\left(c_{2}^{2}-c_{3}\right) e_{n}^{3}+\left(-4 c_{2}^{3}+7 c_{2} c_{3}-3 c_{4}\right) e_{n}^{4}+ \\
\left(8 c_{2}^{4}-20 c_{2}^{2} c_{3}+10 c_{2} c_{4}+6 c_{3}^{2}-4 c_{5}\right) e_{n}^{5}+O\left(e_{n}^{6}\right) .
\end{gathered}
$$

Using equation (3.3), we can find

$$
\begin{aligned}
y_{n} & =x_{n}-\frac{f\left(x_{n}\right)}{f^{\prime}\left(x_{n}\right)} \\
& =\alpha+c_{2} e_{n}^{2}-2\left(c_{2}^{2}-c_{3}\right) e_{n}^{3}+\left(4 c_{2}^{3}-7 c_{2} c_{3}+3 c_{4}\right) e_{n}^{4}+ \\
& \left(-8 c_{2}^{4}+20 c_{2}^{2} c_{3}-10 c_{2} c_{4}-6 c_{3}^{2}+4 c_{5}\right) e_{n}^{5}+O\left(e_{n}^{6}\right) .
\end{aligned}
$$

Using equation (3.4), the Taylor's series of $f\left(y_{n}\right)$ is given by

$$
\begin{gathered}
f\left(y_{n}\right)=c_{2} e_{n}^{2}-2\left(c_{2}^{2}-c_{3}\right) e_{n}^{3}+\left(5 c_{2}^{3}-7 c_{2} c_{3}+3 c_{4}\right) e_{n}^{4}+ \\
\left(-12 c_{2}^{4}+24 c_{2}^{2} c_{3}-10 c_{2} c_{4}-6 c_{3}^{2}+4 c_{5}\right) e_{n}^{5}+O\left(e_{n}^{6}\right) .
\end{gathered}
$$

Using equations (3.1), (3.2) and (3.5), we get

$$
\begin{gathered}
f^{\prime}\left(x_{n}\right)\left(f\left(x_{n}\right)+2 f\left(y_{n}\right)\right)=e_{n}+5 c_{2} e_{n}^{2}+\left(2 c_{2}^{2}+8 c_{3}\right) e_{n}^{3}+\left(2 c_{2}^{3}+5 c_{2} c_{3}+11 c_{4}\right) e_{n}^{4}+ \\
\left(-4 c_{2}^{4}+8 c_{2}^{2} c_{3}+6 c_{2} c_{4}+3 c_{3}^{2}+14 c_{5}\right) e_{n}^{5}+O\left(e_{n}^{6}\right) .
\end{gathered}
$$

Using equations (3.2), (3.5) and (3.6), the error term for algorithm 2.3 is given as:

$$
e_{n+1}=-3 c_{2}^{3} e_{n}^{4}+\left(20 c_{2}^{4}-16 c_{2}^{2} c_{3}\right) e_{n}^{5}+O\left(e_{n}^{6}\right) .
$$

This completes the proof. 


\section{Numerical examples}

In this section, we explore the validity and efficiency of newly proposed optimal fourthorder iterative method (algorithm 2.3) (AM1) by considering some standard nonlinear equations. We compare AM1 with the standard Newton's method (NM), Sharma and Behl method (equation 1.4) (SB), Noor and Gupta method (equation 1.3) (NG) and recently developed method by Li (equation 1.5) (LI). The numerical comparison is presented in the following table, whereas the graphical behavior is reflected in Fig. 01 to Fig. 08. We use Maple-18 and Matlab softwares for numerical and graphical comparisons, respectively, taking $\left(\left|x_{n+1}-x_{n}\right|+\left|f\left(x_{n}\right)\right|\right)<\epsilon$ as stopping criteria, where $\epsilon=10^{-15}$ represents tolerance. Both comparative studies clearly indicate that the newly developed method performs better.

In the following table, NFE denotes the total number of functional evaluations required to reach the desired result.

\begin{tabular}{|c|c|c|c|c|c|c|c|}
\hline$f(x)$ & $x_{\circ}$ & Method & $n$ & $x[k]$ & $f\left(x_{n}\right)$ & $\left(\left|x_{n+1}-x_{n}\right|\right)$ & $N F E$ \\
\hline \multirow{5}{*}{$x^{3}-x-8$} & \multirow{5}{*}{-1.55} & $\overline{N M}$ & 13 & 2.1663127473977890 & $2.906126 e^{-16}$ & $3.602407 e^{-11}$ & $\overline{26}$ \\
\hline & & $S B$ & 10 & 2.1663127473977890 & $2.906126 e^{-16}$ & $7.131811 e^{-13}$ & 30 \\
\hline & & $N G$ & 12 & 2.1663127473977890 & $2.906126 e^{-16}$ & $6.118864 e^{-} 11$ & 48 \\
\hline & & $L I$ & 6 & 2.1663127473977890 & $2.906126 e^{-16}$ & $3.189469 e^{-14}$ & 18 \\
\hline & & $A M 1$ & 4 & 2.1663127473977891 & $1.598486 e^{-15}$ & $2.511896 e^{-09}$ & 12 \\
\hline \multirow{5}{*}{$x^{3}-e^{-\sin x}-2$} & \multirow{5}{*}{-1.03} & $\overline{N N M}$ & $\overline{99}$ & 1.3348032769765693 & $6.102066 e^{-17}$ & $2.694072 e^{-12}$ & $\overline{18}$ \\
\hline & & $S B$ & 8 & 1.3348032769765693 & $6.102066 e^{-17}$ & $5.114977 e^{-10}$ & 24 \\
\hline & & $N G$ & 6 & 1.3348032769765693 & $6.102066 e^{-17}$ & $6.466281 e^{-08}$ & 24 \\
\hline & & $L I$ & 9 & 1.3348032769765693 & $6.102066 e^{-17}$ & $8.452116 e^{-05}$ & 27 \\
\hline & & $A M 1$ & 4 & 1.3348032769765693 & $6.102066 e^{-17}$ & $1.131499 e^{-10}$ & 12 \\
\hline \multirow{5}{*}{$\ln \left(x e^{x}+1\right)$} & \multirow{5}{*}{0.9} & $\overline{N N M}$ & $\overline{5}$ & $\overline{0.0000000000000000}$ & $5.268150 e^{-22}$ & $3.245967 e^{-11}$ & 10 \\
\hline & & $S B$ & 7 & 0.0000000000000000 & $1.281677 e^{-22}$ & $2.264224 e^{-11}$ & 21 \\
\hline & & $N G$ & 3 & 0.0000000000000004 & $1.059893 e^{-21}$ & $1.618480 e^{-07}$ & 12 \\
\hline & & $L I$ & 3 & 0.0000000000000000 & $1.133586 e^{-34}$ & $4.829742 e^{-09}$ & 9 \\
\hline & & $A M 1$ & 3 & 0.0000000000000000 & $3.115512 e^{-39}$ & $3.019079 e^{-10}$ & 9 \\
\hline \multirow{5}{*}{$\sin ^{-1}(x-1)$} & \multirow{5}{*}{0.4} & 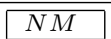 & $\overline{4}$ & 1.0000000000000000 & $0.000000 e^{+00}$ & $2.945940 e^{-12}$ & 8 \\
\hline & & $S B$ & 3 & 1.0000000000000000 & $0.000000 e^{+\infty 0}$ & $3.248117 e^{-07}$ & 9 \\
\hline & & $N G$ & 3 & 1.0000000000000000 & $0.000000 e^{+00}$ & $1.009696 e^{-10}$ & 12 \\
\hline & & $L I$ & 3 & 1.0000000000000000 & $0.000000 e^{+00}$ & $1.467463 e^{-12}$ & 9 \\
\hline & & $A M 1$ & 2 & 1.0000000000000000 & $0.000000 e^{+00}$ & $3.308688 e^{-03}$ & 6 \\
\hline \multirow{5}{*}{$\tan ^{-1} x$} & \multirow{5}{*}{0.4} & $\overline{N N M}$ & 4 & $\overline{0.0000000000000000}$ & $2.316939 e^{-40}$ & $7.030754 e^{-14}$ & 8 \\
\hline & & $S B$ & 3 & 0.0000000000000000 & $2.984464 e^{-24}$ & $3.296218 e^{-08}$ & 9 \\
\hline & & $N G$ & 3 & 0.0000000000000068 & $5.306719 e^{-64}$ & $2.602566 e^{-13}$ & 12 \\
\hline & & $L I$ & 3 & 0.0000000000000000 & $6.666854 e^{-15}$ & $1.974363 e^{-03}$ & 6 \\
\hline & & $A M 1$ & 2 & 0.0000000000000000 & $1.161341 e^{-21}$ & $1.082520 e^{-03}$ & 6 \\
\hline \multirow{5}{*}{$\ln \left(x^{2}+e^{X}\right)$} & \multirow{5}{*}{0.7} & $\overline{N N M}$ & 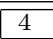 & $\overline{0.0000000000000000}$ & $9.221142 e^{-30}$ & $3.024373 e^{-10}$ & 8 \\
\hline & & $S B$ & 3 & 0.0000000000000000 & $1.073600 e^{-18}$ & $2.953597 e^{-06}$ & 9 \\
\hline & & $N G$ & 3 & 0.0000000000000000 & $1.367087 e^{-48}$ & $4.149614 e^{-10}$ & 12 \\
\hline & & $L I$ & 3 & 0.0000000000000022 & $5.898270 e^{-55}$ & $2.542140 e^{-11}$ & 9 \\
\hline & & $A M 1$ & 2 & 0.0000000000000000 & $8.293687 e^{-15}$ & $1.388499 e^{-02}$ & 6 \\
\hline \multirow{5}{*}{$x^{3}+x^{2}+x-2$} & \multirow{5}{*}{-1.32} & $N M$ & 9 & 0.8105357137661368 & $1.846549 e^{-17}$ & $3.715524 e^{-10}$ & 18 \\
\hline & & $S B$ & 8 & 0.8105357137661368 & $1.846549 e^{-17}$ & $9.630194 e^{-14}$ & 24 \\
\hline & & $N G$ & 6 & 0.8105357137661368 & $1.846549 e^{-17}$ & $2.895097 e^{-08}$ & 24 \\
\hline & & $L I$ & 6 & 0.8105357137661368 & $1.846549 e^{-17}$ & $1.345698 e^{-13}$ & 18 \\
\hline & & $A M 1$ & 4 & 0.8105357137661368 & $1.846549 e^{-17}$ & $4.484225 e^{-11}$ & 12 \\
\hline \multirow{5}{*}{$\ln \left(x^{2}+e^{x}\right)$} & \multirow{5}{*}{2.2} & $\overline{N M}$ & 6 & 0.7145563847430097 & $1.504888 e^{-18}$ & $4.415567 e^{-10}$ & 12 \\
\hline & & $S B$ & 4 & 0.0000000000000042 & $4.227211 e^{-15}$ & $9.194793 e^{-08}$ & 12 \\
\hline & & $N G$ & 4 & 0.7145563847430097 & $1.504888 e^{-18}$ & $5.987244 e^{-12}$ & 16 \\
\hline & & $L I$ & 5 & 0.7145563847430097 & $1.504888 e^{-18}$ & $8.504755 e^{-10}$ & 15 \\
\hline & & $A M 1$ & 3 & 0.0000000000000000 & $0.000000 e^{+00}$ & $1.022619 e^{+03}$ & 9 \\
\hline
\end{tabular}

It is obvious from the above results that, generally, each method converges for the considered test problems. It is notable that the number of functional evaluations per iteration required for the methods NM, SB, NG, LI, and AM1 are 2, 3, 4, 3 and 3 respectively, which clearly indicates that the computational cost of the proposed method is least as it converges in least number of iterations. 


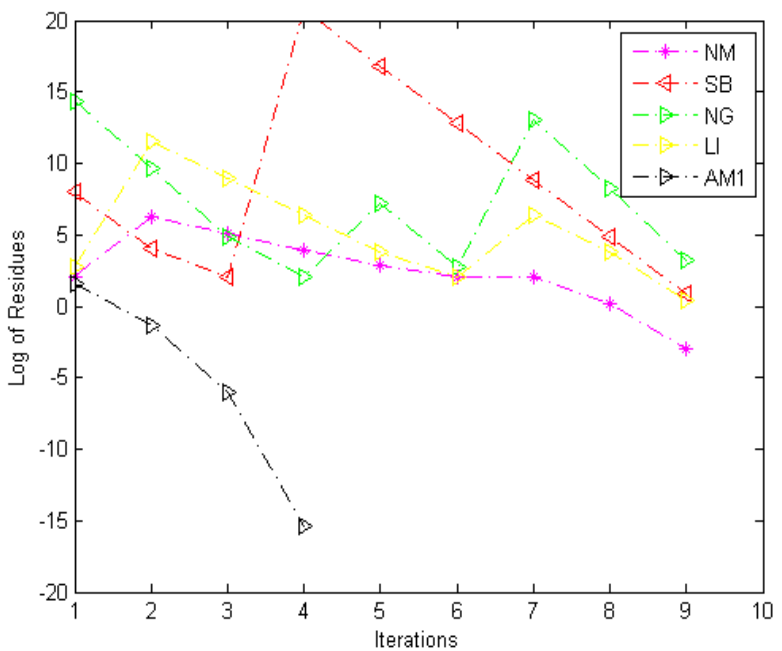

Figure 1. $f(x)=x^{3}-x-8$

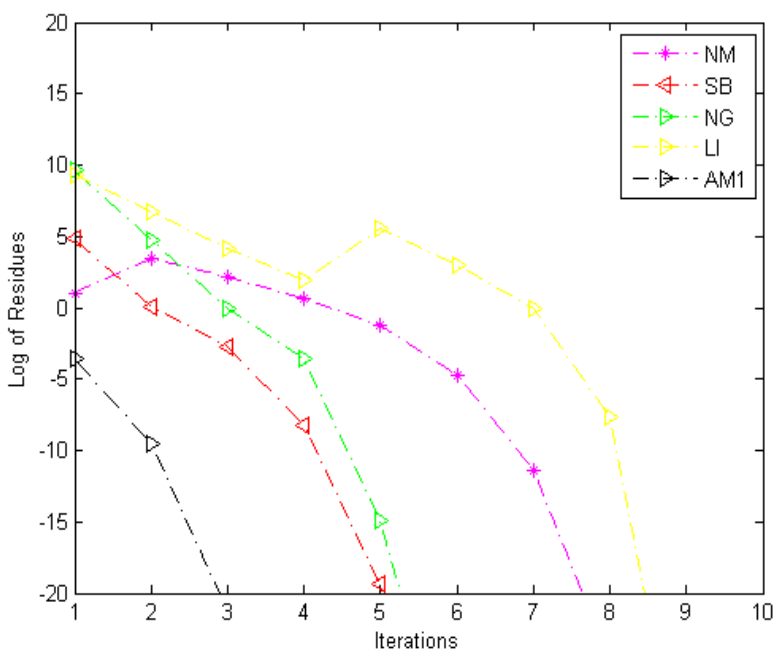

Figure 2. $f(x)=x^{3}-e^{-\sin x}-2$ 


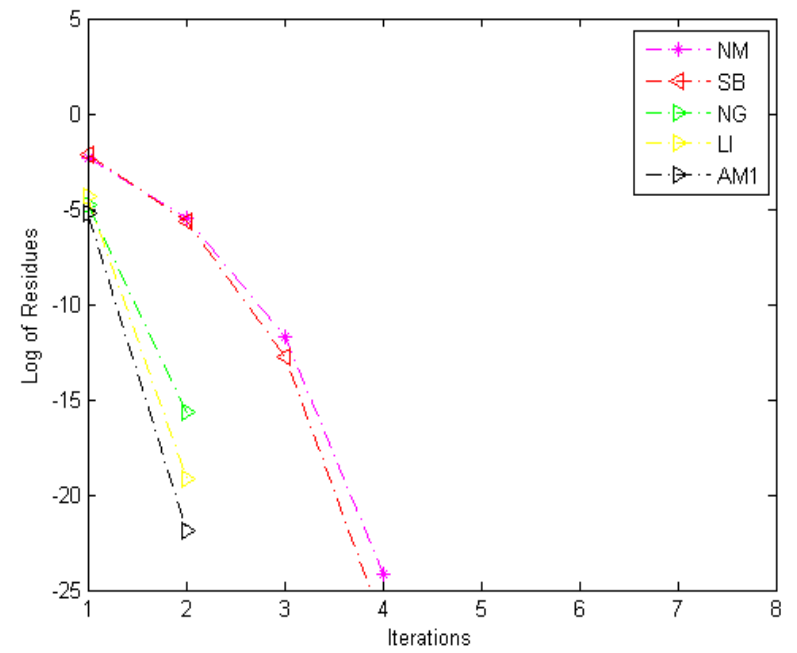

Figure 3. $f(x)=\ln \left(x e^{x}+1\right)$

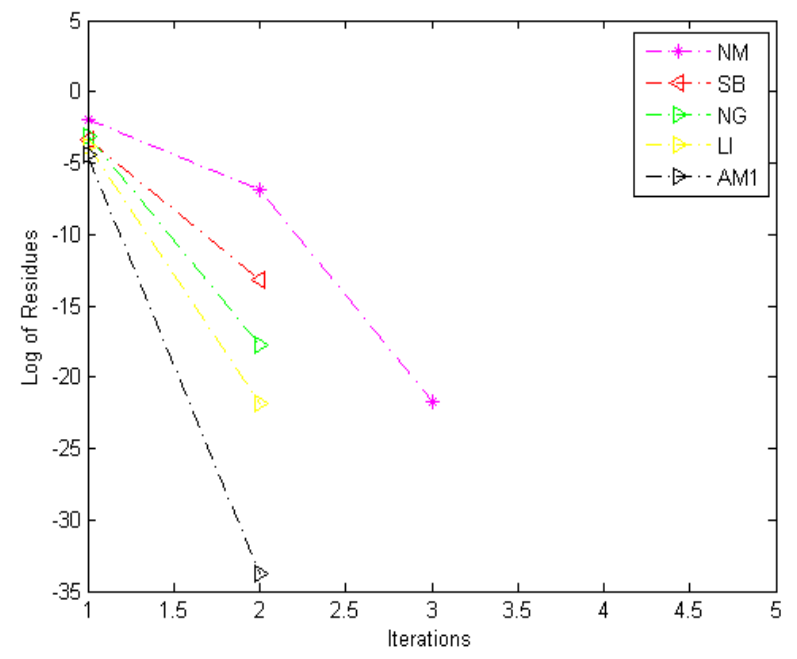

Figure 4. $f(x)=\sin ^{-1}(x-1)$ 


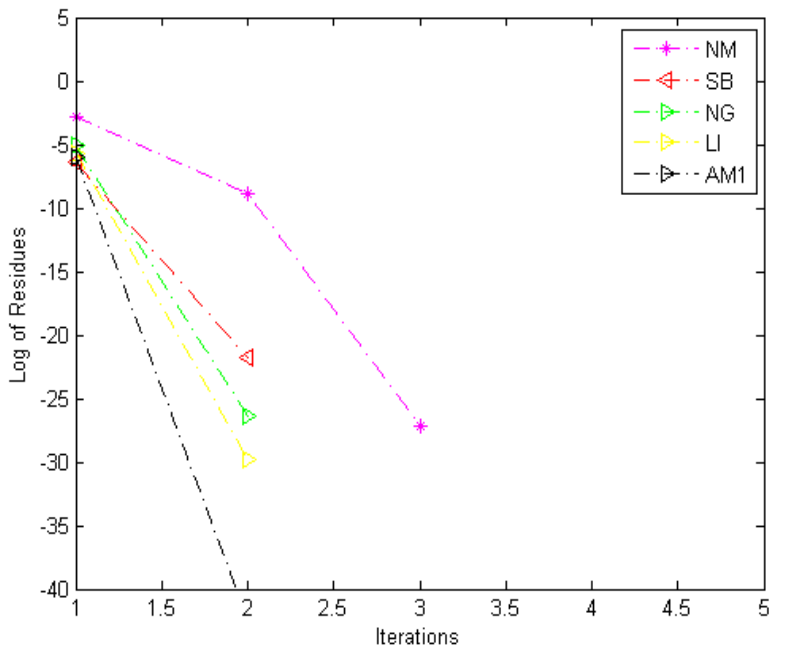

Figure 5. $f(x)=\tan ^{-1} x$

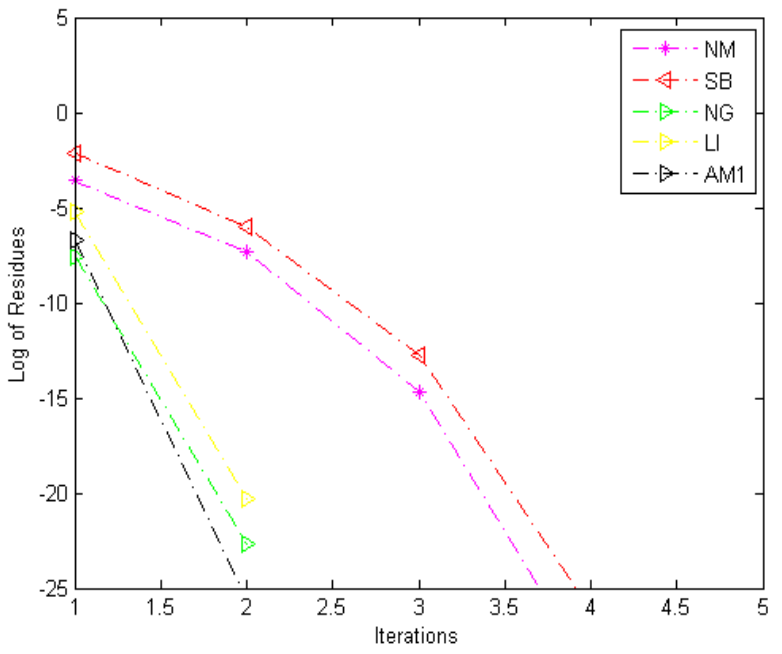

Figure 6. $f(x)=\ln \left(x^{2}+e^{x}\right)$ 


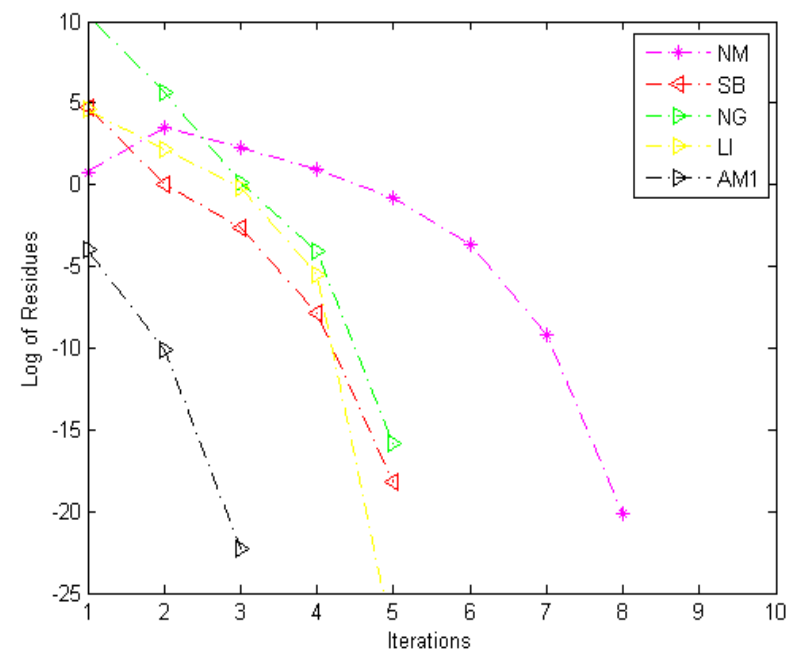

Figure 7. $f(x)=x^{3}+x^{2}+x-2$

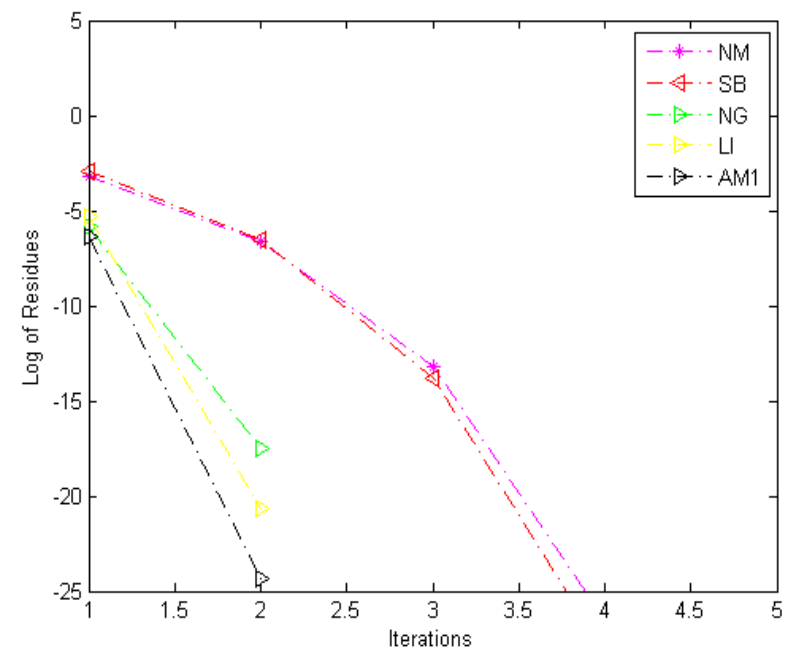

Figure 8. $f(x)=\ln \left(x^{2}+e^{X}\right)$ 


\section{Dynamical study}

Kalantary [39], is the pioneer in the study of polynomiography, which is the art and science of visualization of the roots of complex polynomials. Polynomiography has diverse applications in science, arts, engineering and industries, especially in textile industry. In this section, Fig. 09 to Fig. 16 represent the polynomiographs of certain complex polynomials in the context of newly developed optimal fourth-order iterative method.

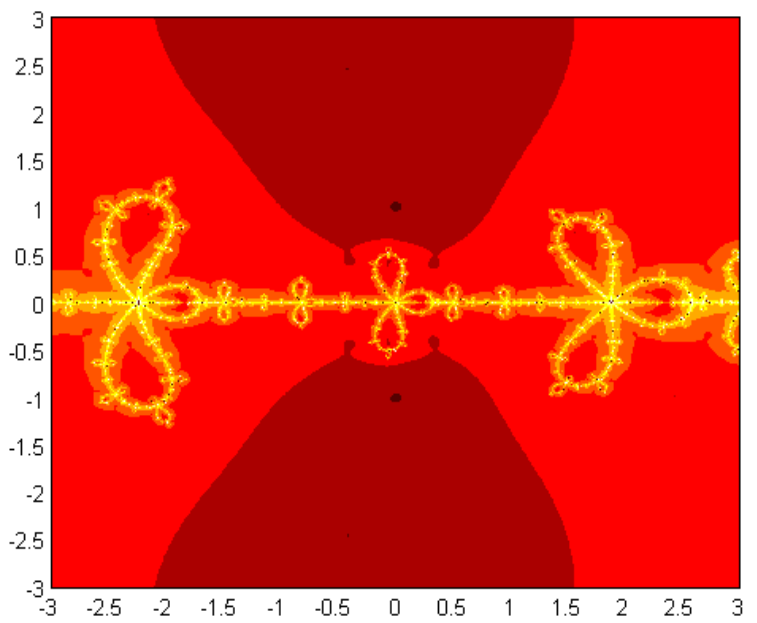

Figure 9. Polynomiograph of $z^{2}+1$

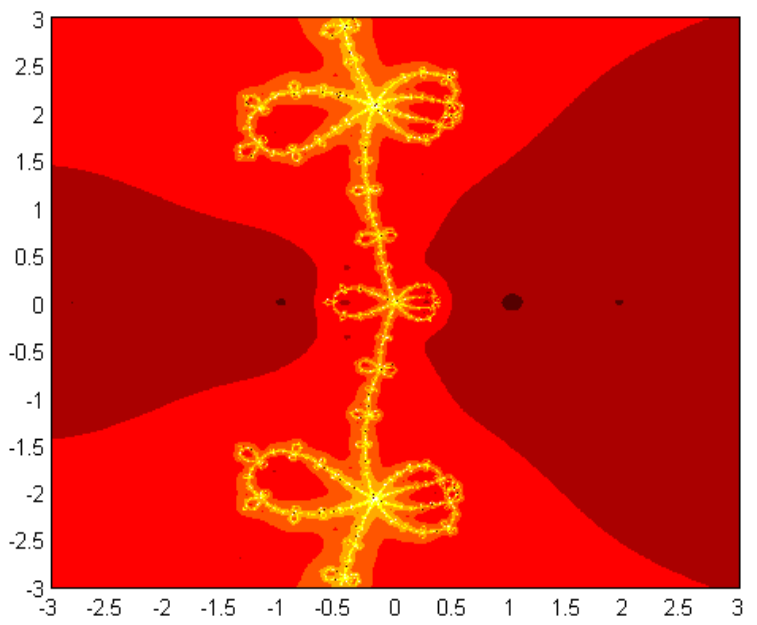

Figure 10. Polynomiograph of $z^{2}-1$ 


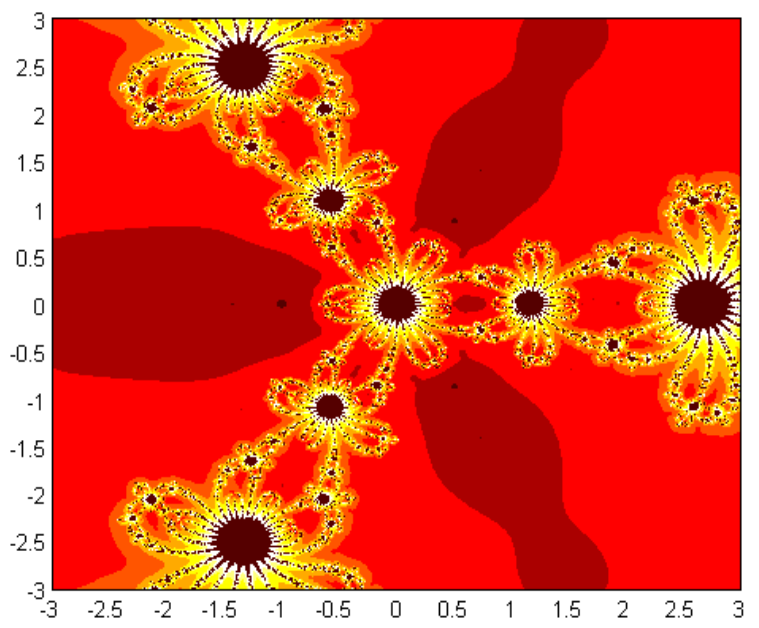

Figure 11. Polynomiograph of $z^{3}+1$

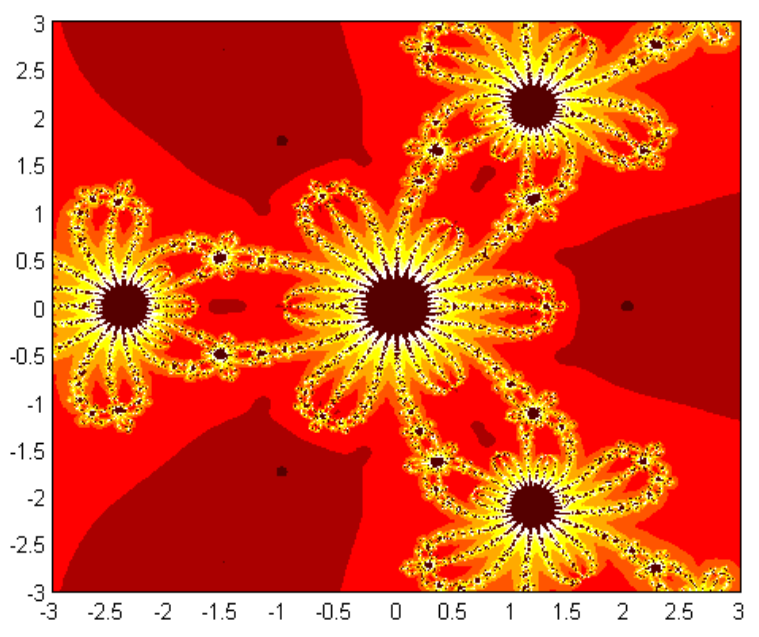

Figure 12. Polynomiograph of $z^{3}+8$ 


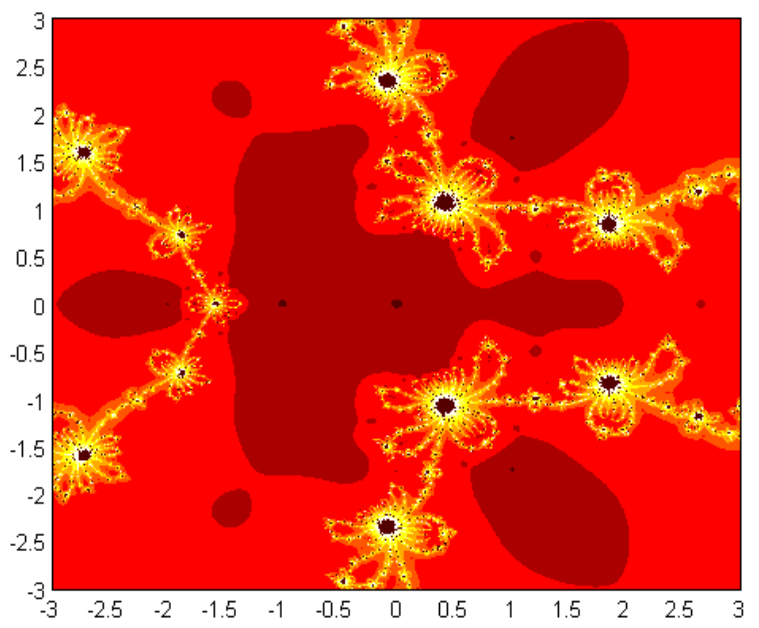

Figure 13. Polynomiograph of $z^{4}+z^{3}+8 z+8$

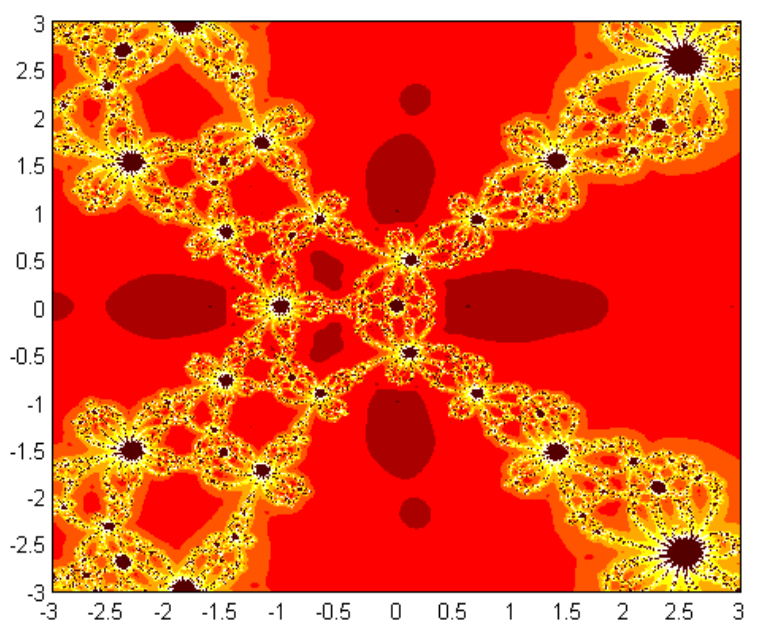

Figure 14. Polynomiograph of $z^{4}+z^{3}+z-1$ 


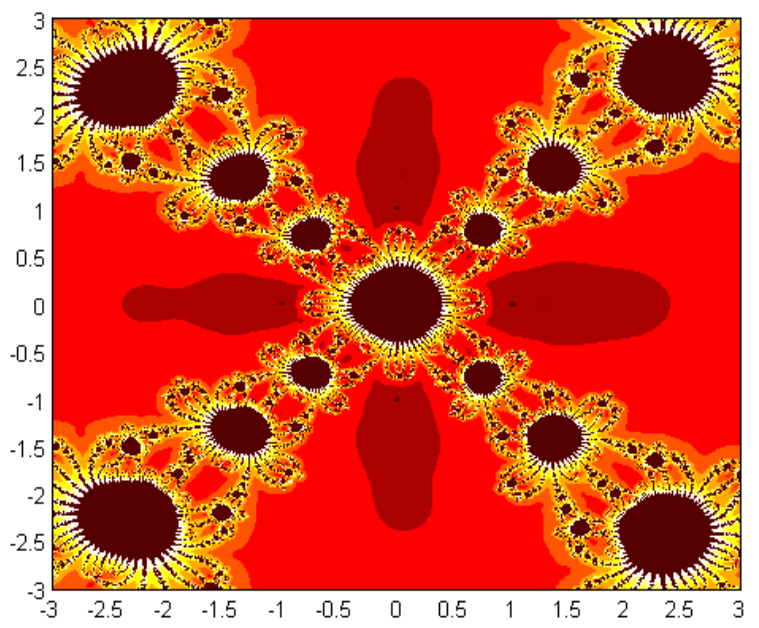

Figure 15. Polynomiograph of $z^{4}-1$

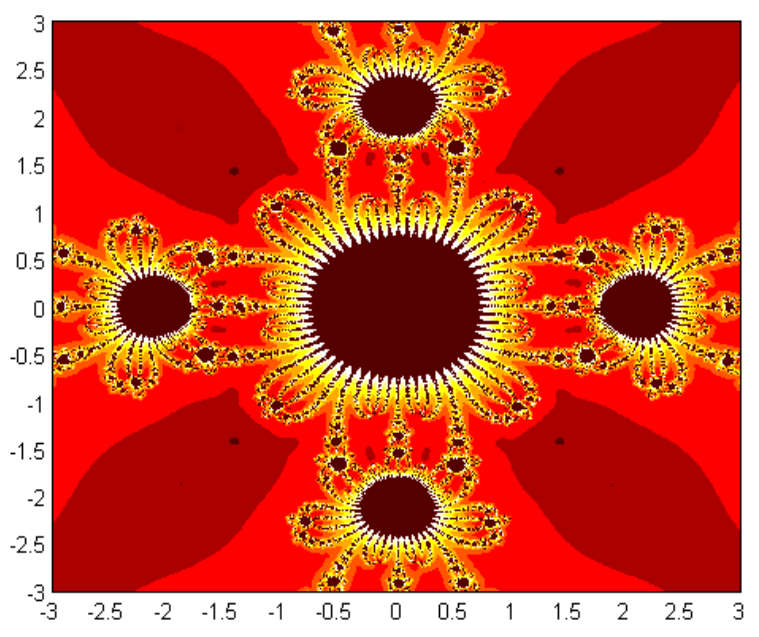

Figure 16. Polynomiograph of $z^{4}+16$ 


\section{Conclusion}

A new two-step optimal fourth-order iterative method, for simple roots of nonlinear equations, based on the technique of linear combination has been introduced in this article. The efficiency of the newly developed method has been demonstrated both numerically and graphically by comparing the same with standard Newton's method and various other methods of same domain. The visualization process has been exhibited by exploring the polynomiographs in the context of some complex polynomials. The study in the previous section reveals the novelty of the proposed method in the sense that it has better basins of attraction in certain cases.

Acknowledgment. The authors are extremely grateful to the reviewers for their valuable remarks and suggestions, which certainly have improved the quality of the paper.

\section{References}

[1] S. Abbasbandy, Improving Newton-Raphson method for nonlinear equations by modified Adomian decomposition method, Appl. Math. Comput. 145, 887-893, 2003.

[2] F. Ali, W. Aslam and A. Rafiq, Some new iterative techniques for the problems involving nonlinear equations, Int. J. Comput. Methods, 16, 1950037 (18 pages), 2019.

[3] F. Ali, W. Aslam, K. Ali, M. A. Anwar and A. Nadeem, New family of iterative methods for solving nonlinear models, Discrete Dyn. Nat. Soc . 9619680, 12 pages, 2018.

[4] M. Ali, N. Anjum and Q.T. Ain, Homotopy Perturbation Method for the Attachment Oscillator Arising in Nanotechnology, Fibers Polym. 22, 1601-1606, 2021.

[5] N. Anjum and J.H. He, Analysis of nonlinear vibration of nano / microelectromechanical system switch induced by electromagnetic force under zero initial conditions, Alex. Eng. J. 59 (6), 4343-4352, 2020.

[6] N. Anjum and J.H. He, Higher-order homotopy perturbation method for conservative nonlinear oscillators generally and microelectromechanical systems' oscillators particularly, Int. J. Mod. Phys. B. 34 (32), 2050313, 2020.

[7] N. Anjum and J.H. He, Homotopy perturbation method for N/MEMS oscillators, Math. Methods Appl. Sci. DOI: 10.1002/mma.6583.

[8] N. Anjum and J.H. He, Nonlinear dynamic analysis of vibratory behavior of a graphene nano/microelectromechanical system, Math. Meth. App. Sci. DOI: 10.1002/mma.6699.

[9] N. Anjum and J.H. He, Two Modifications of the Homotopy Perturbation Method for Nonlinear Oscillators", J. App. Compu. Mech. 6, Special Issue, 1420-1425, 2020.

[10] N. Anjum, J.H. He, Q.T. Ain and D. Tian, Li-He's modified homotopy perturbation method for doubly-clamped electrically actuated microbeams-based microelectromechanical system, Facta Univ. Ser.: Mech. Eng. DOI:10.22190/FUME210112025A.

[11] N. Anjum, M. Suleman and D. Lu, Numerical iteration for nonlinear oscillators by Elzaki transform, J. Low Freq. Noise Vib. Act. Control, 39 (4), 879-884, 2020.

[12] E. Babolian and J. Biazar, Solution of nonlinear equations by modified Adomian decomposition method, Appl. Math. Comput. 132, 167-172, 2002.

[13] S. Bhalekar and V. Daftardar-Gejji, Convergence of new iterative method, Int. J. Differ. Equ. 2011, 989065, 10 pages, 2011.

[14] C. Chun, Some fourth-order iterative methods for solving nonlinear equations, Appl. Math. Comput. 195 (2), 454-459, 2018.

[15] V. Daftardar-Gejji and H. Jafari, An iterative method for solving nonlinear functional equations, J. Math. Anal. Appl. 316 (2), 753-763, 2006.

[16] M. Fahad, M. Nazeer, W. Kang and C.Y. Jung, A fixed point type iterative method and its dynamical behavior, Panam. Math. J. 27 (4), 86-99, 2017. 
[17] M. Frontini and E. Sormani, Third-order methods from quadrature formulae for solving systems of nonlinear equations, Appl. Math. Comput. 149, 771-782, 2004.

[18] C.H. He, An introduction to an ancient Chinese algorithm and its modification, Int. J. Num. Meth. Heat Fluid Flow, 26 (8), 2486-2491, 2016.

[19] C.H. He, C. Liu and K.A. Gepreel, Low frequency property of a fractal vibration model for a concrete beam, Fractals, 29 (05), 2021.

[20] C.H. He, Y. Shen and F.Y. Ji, Taylor series solution for fractal Bratu-type equation arising in electrospinning process, Fractals, 28 (1), 2050011, 2020.

[21] C.H. He, C. Liu, J.H. He, H. Mohammad-Sedighi, A. Shokri and K.A. Gepreel, A fractal model for the internal temperature response of a porous concrete, Appl. Comput. Math. 20 (2), 2021.

[22] C.H. He, C. Liu, J.H. He, A.H. Shirazi and H. Mohammad-Sedighi, Passive Atmospheric water harvesting utilizing an ancient Chinese ink slab and its possible applications in modern architecture, Facta Univ. Ser.: Mech. Eng., 19 (2), 229-239, 2021.

[23] J.H. He, Taylor series solution for a third order boundary value problem arising in architectural engineering, Ain Shams Eng. J. 11 (4), 1411-1414, 2020.

[24] J.H. He and Y.O. El-Dib, Homotopy perturbation method for Fangzhu oscillator, J. Math. Chem. 58 (10), 2245-2253, 2020.

[25] J.H. He and Y.O. El-Dib, Homotopy perturbation method with three expansions, J. Math. Chem. 59, 1139-1150.

[26] J.H. He and Y.O. El-Dib, Periodic property of the time-fractional Kundu-MukherjeeNaskar equation, Results Phys. 19, 103345, 2020.

[27] J.H. He and Y.O. El-Dib, The enhanced homotopy perturbation method for axial vibration of strings, Facta Univ. Ser.: Mech. Eng. DOI: 10.22190/FUME210125033H.

[28] J.H. He and Y.O. El-Dib, The reducing rank method to solve third-order Duffing equation with the homotopy perturbation, Numer. Methods Partial Differ. Equ. 37 (2), 2021.

[29] J.H. He, N. Anjum and P.S. Skrzypacz, A Variational Principle for a Nonlinear Oscillator Arising in the Microelectromechanical System, J. Appl. Comput. Mech. 7 (1), 78-83, 2021.

[30] J.H. He, F.Y. Ji and H. Mohammad-Sedighi, Difference equation vs differential equation on different scales, Int. J. Num. Meth. Heat Fluid Flow, 31 (1), 391-401, 2021.

[31] J.H. He, S.J. Kou and C.H. He, Fractal oscillation and its frequency-amplitude property, Fractals, DOI:10.1142/S0218348X2150105X.

[32] J.H. He, D. Nurakhmetov and P. Skrzypacz, Dynamic pull-in for microelectromechanical device with a current-carrying conductor, J. Low Freq. Noise Vib. Act. Control, 40 (2), 1059-1066, 2021.

[33] J.H. He, N. Qie and C.H. He, Solitary waves travelling along an unsmooth boundary, Results Phys. 24, 104104, 2021.

[34] J.H. He, N. Qie, C.H. He and T. Saeed, On a strong minimum condition of a fractal variational principle, Appl. Math. Lett. 119, 107199, 2021.

[35] J.H. He, P.S. Skrzypacz, Y.N. Zhang and J. Pang, Approximate periodic solutions to microelectromechanical system oscillator subject to magneto static excitation, Math. Methods Appl. Sci. DOI: 10.1002/mma.7018.

[36] J.H. He, W.F. Hou, N. Qie, K.A. Gepreel, A.H. Shirazi and H. Mohammad-Sedighi, Hamiltonian-based frequency-amplitude formulation for nonlinear oscillators, Facta Univ. Ser.: Mech. Eng. DOI: 10.22190/FUME 201205002H.

[37] S. Huang, A. Rafiq, M.R. Shahzad and F. Ali, New higher order iterative methods for solving nonlinear equations, Hacettepe J. Math. Stat. 47 (1), 77-91, 2018. 
[38] M.M.M. Joubari, D.D. Ganji and H.J. Jouybari, Determination of Periodic Solution for Tapered Beams with Modified Iteration Perturbation Method, J. Appl. Comput. Mech. 1 (1), 44-51, 2015.

[39] B. Kalantary, Polynomial Root-Finding and Polynomiography, World Sci. Publishing Co., Hackensack, 2009.

[40] W. Kang, M. Nazeer, A. Rafiq and C.J. Jung, A new third-order iterative method for scalar nonlinear equations, Int. J. Math. Anal. 8 (43), 2141-2150, 2014.

[41] H.T. Kung and J.F. Traub, Optimal order of one-point and multi-point iteration, Appl. Math. Comput. 21, 643-651, 1974.

[42] X.J. Li, Z. Liu and J.H. He, A fractal two-phase flow model for the fiber motion in a polymer filling process, Fractals, 28 (5), 2050093, 2020.

[43] M. Nadeem and J.H. He, He-Laplace variational iteration method for solving the nonlinear equations arising in chemical kinetics and population dynamics, J. Math. Chem. 59, 1234-1245, 2021.

[44] M. Nadeem, J.H. He and A. Islam, The homotopy perturbation method for fractional differential equations: part-1 Mohand transform, Int. J. Numer. Methods Heat Fluid Flow, DOI: 10.1108/HFF-11-2020-0703.

[45] M.A. Noor, Iterative methods for nonlinear equations using homotopy perturbation technique, Appl. Math. Inf. Sci. 4 (2), 227-235, 2010.

[46] M.A. Noor, and V. Gupta, Modified Householder iterative method free from second derivatives for nonlinear equations, Appl. Math. Comput. 190, 1701-1706, 2007.

[47] A.M. Ostrowski, Solution of equations in Euclidean and Banach Space, Third Ed., Academic Press, New York, 1973.

[48] F.A. Porta and V. Ptak, Nondiscrete induction and iterative process, Research Notes in Mathematics, Pitman, 103, Boston, 1994.

[49] R. Sharma and A. Bahl, An optimal fourth order iterative method for solving nonlinear equations and its dynamics, J. Complex Anal. 9, 259167-259176, 2015.

[50] S. Li, "Fourth-order iterative method without calculating the higher derivatives for nonlinear equation", J. Algorithm Comput. Technol. 13, 1-8, 2019.

[51] P. Skrzypacz, J.H. He, G. Ellis and M. Kuanyshbay, A simple approximation of periodic solutions to microelectromechanical system model of oscillating parallel plate capacitor, Math. Meth. App. Sci. DOI: 10.1002/mma.6898.

[52] D. Tian, C.H. He and J.H. He, Fractal Pull-in Stability Theory for Microelectromechanical Systems, Front. Phys. DOI: 10.3389/fphy.2021.606011.

[53] J.F. Traub, Iterative Methods for the Solution of Equations, Printice Hall, New Jersey, 1964.

[54] M. Turkyilmazoglu, An optimal variational iteration method, Appl. Math. Lett. 24 (5), 762-765, 2011.

[55] M. Turkyilmazoglu, Is homotopy perturbation method the traditional Taylor series expansion, Hacettepe J. Math. Stat. 44 (3), 651-657, 2015.

[56] M. Turkyilmazoglu, Parametrized Adomian Decomposition Method with Optimum Convergence, ACM Trans. Model. Comput. Simul. 27 (4), 2017.

[57] M. Turkyilmazoglu, A simple algorithm for high order Newton iteration formulae and some new variants, Hacettepe J. Math. Stat. 49 (1), 425-438, 2020.

[58] S. Weerakon and T.J.I. Fernando, A variant of Newton $s$ method with accelerated third-order convergence, Appl. Math. Lett. 13, 87-93, 2000. 